\title{
O MONÓLOGO DO ZOO: NOS CAMINHOS DE UMA NARRATIVA DIGITAL?
}

\section{THE ZOO MONOLOGUE: ON THE WAYS OF A DIGITAL NARRATIVE?}

\author{
Monica Érika Pardin Steinert ${ }^{1}$
}

\begin{abstract}
Resumo: Zoológicos são instituições científicas porque encerram relevantes coleções faunísticas, além de repercutirem as características dos biomas de origem dos animais neles presentes. Disto provém sua potencialidade pedagógica extensível para a educação básica, com possível aproveitamento desses lugares como ambientes não formais de ensino. Um ambiente não formal de ensino, mas com potencialidade para processos de ensino-aprendizagem que vai ao encontro da proposição sempre vanguardista de turismo educativo feita por Célestin Freinet. Este trabalho é um relato de experiência sobre uma aula de campo que resultou na construção de uma narrativa digital, que se propõe como um diálogo entre protagonistas escolares e institucionais no sentido de modificar uma realidade no seio de um modelo de crise socioambiental.
\end{abstract}

Palavras-chave: Ambiente não-formal; Zoológico; Mídia; TDIC; Comunicação.

\begin{abstract}
Zoos are scientific institutions because they contain important faunal collections, as well as repercussions of the characteristics of the biomes of origin of the animals present in them. From this comes its pedagogical potential that can be extended to basic education, with the possible use of these places as non-formal teaching environments. A non-formal teaching environment, but with potential for teachinglearning processes that meets Célestin Freinet's always avant-garde proposition of educational tourism. This work is an experience report about a field class that resulted in the construction of a digital narrative, which is proposed as a dialogue between school and institutional protagonists in order to modify a reality within a socioenvironmental crisis model.
\end{abstract}

Keywords: Non-formal environment; Zoo; Media; TDIC; Communication.

\section{Introdução}

Zoológicos são lugares aprazíveis para espairecer e observar a beleza e peculiaridades dos animais. Diante de tal assertiva situada no âmbito do senso comum, esses locais povoam memórias, como típicos ambientes de visitação familiar e recreação. Essas memórias, em tempos anteriores ao advento da Era Digital, eram exprimidas por intermédio de narrativas verbais, fotografias e mesmo filmagens amadoras. Convém mencionar que o registro imagético, pela ação do tempo se desbota no papel fotográfico,

\footnotetext{
${ }^{1}$ Mestra em Ensino de Ciências Naturais pela Universidade Federal de Mato Grosso (UFMT). Docente de Biologia na Educação Básica pela Secretaria de Estado de Educação, Esporte e Lazer de Mato Grosso (SEDUC-MT), Cuiabá, Mato Grosso E-mail: pardiste76@ hotmail.com
} 
muitas narrativas verbais cessaram ou foram esquecidas e o próprio vídeo cassete desapareceu.

Com o advento da revolução provocada pela ascensão das redes de internet comercial nos anos 1990, dispositivos digitais de mídias e comunicação, seja desktop ou portáteis, foram maciçamente entronizados nas sociedades e permanecem em contínuo estado de inovação. O celular é o elemento representativo neste cenário tecnológico, pois permitiu, entre outros eventos, tornar a internet ubíqua. E, paralelamente ao avanço tecnológico nas ferramentas de mídia e comunicação, a percepção sobre o zoológico também se modificou, como sendo um ambiente característico de confinamento e sofrimento para animais silvestres. Isso demonstra que a própria concepção de zoológico está em modificação mundo afora, configurando que muitos modelos ainda existentes desses espaços se mostram obsoletos no todo.

Essas discussões não fogem à realidade do zoológico da Universidade Federal de Mato Grosso (UFMT), único em todo o mundo situado dentro de uma universidade. Este zoológico possui animais de três biomas brasileiros de grande importância, relativamente à biodiversidade, tais como Cerrado, Pantanal e Floresta Amazônica.

Buscando-se uma aproximação da escola com o zoológico, este trabalho tem o objetivo de relatar a experiência de construção de uma narrativa digital a partir de uma aula visita. Os estudantes participantes da proposta tiveram oportunidade de perceber uma abordagem alternativa para uma aula em ambientes não formais, incorporando o uso de tecnologias digitais ao processo. A proposta pedagógica da aula visita teve como objetivo principal a pretensa construção de um diálogo institucional entre a educação básica e os mantenedores do zoológico, de forma a repercutir na comunidade como um limiar para a melhoria da imagem pública do local.

\section{Fundamentação teórica}

A expressão "espaço não formal" tem sido utilizada na atualidade por pesquisadores em Educação, docentes de diversas áreas do conhecimento e profissionais que trabalham com divulgação científica para descrever lugares, alternativos em relação a sala de aula, onde é possível desenvolver atividades educativas. Os espaços formais de educação são os recintos escolares propriamente ditos, enquanto que os espaços não formais seriam ambientes institucionais ou não institucionais. Ambientes não formais de 
DOI: http://dx.doi.org/10.33238/ReBECEM.2019.v.3.n.1.21961

ensino institucionalizados são exemplificados por museus, centros de Ciências, parques ecológicos e zoobotânicos, jardins botânicos, planetários, institutos de pesquisa, aquários e zoológicos. Um ambiente natural ou urbano destituído de estruturação institucional, mas que também possibilita a adoção de práticas educativas englobaria a categoria ambiente não formal não institucional, como é o caso do teatro, casa, rua, parque, cinema, campo de futebol e outros (JACOBUCCI, 2008). Sendo assim, é possível classificar o zoológico como uma insituição não formal de ensino, de âmbito institucional. A finalidade de existência desses locais não é o provimento de educação em si, entretanto, nada impede que neles aconteçam processos de ensino-aprendizagem.

As atividades práticas escolares desenvolvidas em espaços não formais recebem diferentes nomes que variam conforme a sua natureza, tendo em comum a sua execução em um ambiente não escolar. Elas incluem aulas de campo, aulas de educação ambiental, estudos do meio, saídas de campo, visitas externas, excursões, visitas orientadas e passeios (GOLDSCHMIDT, 2016). Ainda segundo a autora, o zoológico brasileiro que teve pioneirismo no desenvolvimento de atividades educativas foi o Zoológico Quinzinho de Barros, localizado na cidade paulista de Sorocaba. Esse zoológico possui relevante infraestrutura de atendimento a visitantes e numerosas espécies de fauna nativa e exótica. Caminhando pelo local, é possível constatar aparatos para viabilização de educação ambiental, expressos na abundância e clareza das placas de identificação dos recintos, no pequeno anfiteatro próximo ao recinto dos hipopótamos destinado a preleções e, até mesmo, no simbólico "cemitério" de espécies extintas da fauna brasileira, localizado próximo a quiosques construídos para a realização de piqueniques. Este zoológico cobra ingressos para visitação a valores simbólicos, com arrecadações destinadas à sua manutenção. Um lugar com zeloso paisagismo e conforto para as pessoas recrearem. No entanto, não foge à memória da autora deste artigo a contemplação de um jaguarundi (Puma yagouaroundi) confinado em um pequeno recinto, manifestando um comportamento inerente aos ambientes de cativeiro caracterizado por um incessante ir e vir. A observação mantém consonância com o argumento de Goldschmidt (2016) onde: 
DOI: http://dx.doi.org/10.33238/ReBECEM.2019.v.3.n.1.21961

para conservação, pesquisas e práticas educacionais. Desta forma, os zoológicos, como espaços não formais, têm sido cada vez mais vistos pelos professores, como um recurso acessório para práticas pedagógicas, principalmente relacionadas à zoologia, ecologia, evolução, taxonomia, comportamento, dentre outros (p.61).

Nos Estados Unidos, alguns dos zoológicos mais famosos do mundo estão em dificuldades financeiras e na manutenção de empregos, como consequência da diminuição de suas verbas. Conjugado a isso, houve o clamor social após denúncias como a do documentário Blackfish e muitas pessoas estão evitando doar dinheiro a organizações que mantêm animais confinados em pequenas jaulas. Mesmo que os zoológicos sejam importantes centros de preservação. No entanto, essa tendência não significa o fim dos zoológicos, mas a demanda por uma evolução em seus conceitos e estrutura (FERREIRA, 2014).

Seja como espaço de lazer ou ambiente com potencial educacional, a necessidade econômica de modificar os zoológicos tem inspirado uma onda de criatividade interdisciplinar (FERREIRA, 2014).

Ferreira (2014) refere que o escritório dinamarquês de arquitetura Bjarke Ingels Group (BIG) projeta um novo conceito de zoológico panorâmico chamado Zootopia, que consta em uma concepção alternativa que reduz a interação visual humana com os animais. Outras tendências no segmento são baseadas no uso de webcams em zoológicos para observação remota das atividades dos animais em seus recintos. Na França, zoológicos com "biozonas" ecológicas são projetados para reproduzir fidedignamente os habitats naturais dos animais. Entretanto, existem conservacionistas radicais que defendem a extinção de quaisquer atividades de interação entre animais e seres humanos.

E a mencionada criatividade interdisciplinar reforça que o zoológico é um espaço em que a curiosidade e os sentidos estão aguçados, ao mesmo tempo em que pode estimular o público a refletir sobre as questões ambientais pertinentes em relação a realidade em que estão inseridos. Justamente por essa razão, é importante que as atividades ofertadas pelos zoológicos sejam condizentes com o contexto atual e que englobe as interações entre os aspectos naturais e sociais que caracterizam e determinam o meio ambiente. Todavia, cabe também ao professor refletir sobre as contribuições dos espaços não formais para a formação dos alunos e concretizá-las no planejamento de suas propostas de ensino, tornando essencial o diálogo entre espaços formais e não formais de educação (GOLDSCHIMIDT, 2016). 
DOI: http://dx.doi.org/10.33238/ReBECEM.2019.v.3.n.1.21961

Considerando a realidade, contexto de inserção e necessidade de prover diálogo entre espaços formais e não formais de educação, o zoológico da Universidade Federal de Mato Grosso (UFMT) surte como um cenário ideal para essa proposta. Localizado dentro do campus de Cuiabá, segundo Fredericci (2015) o zoológico "vive uma fase melancólica". Tendo sido inaugurado no ano de 1977, é o único em todo o mundo situado dentro de uma universidade. Possui animais do Cerrado, Pantanal e Floresta Amazônica. Com visitação gratuita, o zoológico sobrevive com parcas verbas federais gerenciadas pela Faculdade de Medicina Veterinária e Zootecnia (FAMEVZ). Sua infraestrutura de suporte a visitantes é rudimentar, havendo calçamento pavimentado, um bebedouro, alguns bancos na área de circulação e lixeiras. Não há lanchonetes e o sanitário é inviável em dias de maior movimentação. Para fazer eventuais refeições, os visitantes devem se deslocar para lanchonetes externas ao zoo, situadas dentro do campus. Muitos recintos não possuem placas de identificação dos animais. O zoológico está embargado pelo IBAMA desde 2009 e envolvido em ações relacionadas ao Ministério Público do Estado de MT. No entanto, paradoxalmente recebe animais machucados e apreendidos pelo referido órgão ambiental. Possui mais de 900 animais, dentre os quais, aves, mamíferos, répteis e espécimes dos biomas Cerrado e Pantanal, tais como a onça-pintada, onça-parda, jaguatirica, veado-catingueiro, jacarés (havendo alguns exemplares albinos no plantel), lobo-guará, tamanduá, anta e outros.

Sendo um patrimônio turístico local consolidado na sociedade cuiabana, o zoológico da UFMT tem padecido com difamação nas mídias. Usando aplicativos de celulares e redes sociais, várias denúncias foram feitas citando suposta negligência com os animais (NEVES, 2016), entre outras queixas.

Diante dessas circunstâncias, o planejamento das atividades nesses espaços, são desafiadores para os professores. Como elaborar uma aula nesses locais que os possibilite cumprir seu objetivo educativo, sem que seja diluído por seu caráter lúdico? (GOLDSCHIMDT, 2016). Como ficar indiferente aos seus problemas e ao depauperamento da instituição nas redes sociais por uma opinião pública muitas vezes leiga e inflamada pelo calor de discursos irresponsáveis?

Nessa perspectiva uma prática educativa deve ser conduzida a partir de uma situação vivenciada (ou constatada) pelas pessoas e que a superação desse contexto, como a definição de uma ação educativa, deve ser coletiva e mediada pela realidade e 
DOI: http://dx.doi.org/10.33238/ReBECEM.2019.v.3.n.1.21961

problemática a ser transformada. Esse potencial transformativo pode criar novas raízes para práticas futuras (MARTINS; RANCURA; OLIVEIRA, 2016).

Martins, Rancura e Oliveira (2016), também destacam que é viável desenvolver ações educativas participativas em instituições de educação não formal que apresentam uma estrutura hierárquica que envolva diversos seguimentos e profissionais. Esse zoológico possui potencialidade para trabalhos conjuntos entre a escola e a equipe de veterinária e zootecnia que o gerencia. O professor de Ciências e Biologia deve animar a articulação dessas propostas educativas porque os zoológicos são centros institucionais científicos por excelência. É, a princípio, um ambiente com acentuado caráter biológico, “[...] pois se trata de uma exposição que tem no seu acervo espécimes vivos" (GOLDSCHIMIDT, 2016, p.65).

E no sentido de estreitar vínculos entre Ciência e População, os conteúdos científicos e tecnológicos devem ser difundidos para além da banalização, propiciando uma cultura científica que capacite os cidadãos a discursarem livremente sobre ciências, com o mínimo de noção sobre os processos e implicações dela em seu cotidiano, como algo desafiador e uma atitude de responsabilidade social. E os professores frequentadores desses espaços educativos devem ter uma formação que lhes permita articular e entrecruzar a cultura científica, o saber popular e o próprio saber com vistas à criação de novos conhecimentos e a sua divulgação de forma consciente e cidadã (JACOBUCCI, 2008).

E no tocante à divulgação de atividades de ensino-aprendizagem, as redes sociais que possibilitam a difusão de mídias audiovisuais, podem ser ferramentas viáveis para a aclamação dessa responsabilidade social mencionada por Jacobucci (2008). Esses canais de comunicação, somados à aptidão dos adolescentes para manipular mídias e dispositivos digitais, podem possibilitar protagonismo social para (e nas) interações com ambientes institucionais não formais de ensino potencialmente educativos, mas em situação de decadência ou desabono social, porque

$\mathrm{Na}$ era da convergência tecnológica, o fenômeno colaborativo coloca em evidência o público que tem participado de mídias sociais digitais. As conexões estabelecidas nestes espaços podem ser superficiais, mas são capazes de mobilizar multidões insatisfeitas com políticas públicas para o transporte, a saúde e a educação (QUADROS; QUADROS JR., 2013, p.7).

Essa mobilização perpassa também uma educação ambiental crítica que deve valorizar a participação, o envolvimento, o sentimento de pertencimento, a confiança e o 
diálogo horizontal entre os sujeitos inseridos no mundo (MARTINS; RANCURA; OLIVEIRA, 2016). O zoológico é um local com potencial para descobertas, vivências únicas e agradáveis, com livre escolha de percursos, que deve ser capaz de instigar os participantes a diferentes problematizações, não apenas de natureza biológica, mas com a troca de ideias, informações, impressões e emoções (GOLDSCHIMDT, 2016). As redes sociais são como uma tela de pintura nova, passível de receber esmeradas pinturas em sua superfície ou traços vulgares e inexpressivos. Sendo assim, as propostas educativas baseadas em ambientes não formais podem ser refletidas no ciberespaço, enquanto rastro de atividades que deverão fomentar críticas e ideias construtivas em seus observadores.

Paulo Freire, por exemplo, defende uma aprendizagem na qual educador e educandos caminham juntos, isenta de memorização mecanizada de conteúdos e pautada em reflexão e ação, autonomia, criticidade e diálogo acerca do que foi visto, formando cidadãos comprometidos com sua ação no mundo, e não apenas reprodutores do conhecimento. A dialogicidade tem força nas proposições freirianas (FORESTI; TEIXEIRA, 2012).

[...] a aprendizagem na Era Digital deve ter como principal elemento a criação de estratégias eficazes de aprendizagem, tendo como processo constituinte a autoria colaborativa, a conectividade e a interatividade, dentro de um contexto de interação, comunicação e feedback. Os educandos devem assumir um papel de nó ativo na rede, e o educador promover e orientar a aprendizagem, com vistas à inteligência coletiva (FORESTI; TEIXEIRA, 2012, p. 67)

Essa inteligência coletiva deve amplificar a cognição social das pessoas sobre o ambiente não formal em foco e repercutir nas produções oriundas dessas práticas. "As atividades devem ser propostas de modo que os contextos, formal e informal, possam ser coordenados e complementares" (VALENTE; ALMEIDA, 2014, p.36). O ciberespaço e as redes sociais baseadas em mídias podem ser o ponto de convergência desses contextos, por intermédio de uma atividade construída coletivamente entre docentes e estudantes, orientada para determinados fins e com a intencionalidade de compor um feedback da atividade realizada em campo.

Se essa experiência informar, sensibilizar e finalmente mobilizar, todos os segmentos envolvidos horizontalmente, não deixará de ter o traço de uma proposta de ensino-aprendizagem participativa. “[...] Essa perspectiva metodológica deve ser entendida como uma busca para a superação da crise socioambiental por meio do diálogo, 
do exercício da democracia, para a consolidação de uma ética de vida" (MARTINS; OLIVEIRA; RANCURA, 2016, p.309).

Aulas em ambientes não formais são consagradas na pedagogia desde o pioneirismo de Célestin Freinet, que se referiu à proposta como "aula-passeio", como sendo uma prática com objetivo de propiciar um estudo do meio. Freinet percebeu o quanto o mundo exterior à sala de aula era atrativo para as crianças, ao contrário do interior da sala de aula (CARDOSO; GATTIBONI, 2015, p.93-94). Onde a possibilidade de usufruir de um espaço não formal de educação científica em crise, de modo alheio à situação de demanda por evolução que urge sem se enquadrar nessa ética de vida posta. Essa superação deve ser baseada em múltiplos diálogos no mundo concreto e virtual, de forma que essas tessituras tenham potencialidade para transformar a realidade.

\section{Aspectos metodológicos}

Este trabalho relata uma experiência pedagógica qualitativa consoante a uma pesquisa-ação. Possui duas facetas dentro deste perfil metodológico: crítica social, pois almeja tornar o mundo um lugar melhor para todos, baseando-se em tolerância, compreensão e cooperação para alcance deste fim; e emancipação, pois almeja mudanças amplas em um dado status quo (TRIPP, 2005).

Em maio do ano de 2015, a autora deste artigo, então docente de Biologia no $2^{\circ}$ ano do ensino médio em uma escola pública situada em Cuiabá, MT, propôs aos estudantes a realização de uma aula de campo. As solicitações constantes pela realização de aulas de campo pelos discentes, visitas prévias da autora ao zoológico e leituras sobre o mesmo na internet, motivaram e permitiram uma sondagem para a articulação da visita. Essa articulação considerou os conteúdos programáticos abordados no currículo de Biologia, tais como Zoologia, Taxonomia, Educação Ambiental e noções de Ecologia. Além dos conteúdos "duros" de Biologia, essa prática pedagógica buscou aproveitar as habilidades artístiscas, de escrita, de relacionamento interpessoal, de interação, de empreendedorismo e de manipulação de dispositivos digitais de mídia e rede de internet dos estudantes.

Assim, os estudantes foram orientados a coletarem informações escritas, fazerem observações no ambiente, realizarem entrevista no zoológico com funcionários, obterem material imagético e entrevistarem visitantes. Toda a coleta posteriormente seria 
DOI: http://dx.doi.org/10.33238/ReBECEM.2019.v.3.n.1.21961

compilada em um vídeo a ser postado na rede social de reprodução de mídia audiovisual Youtube®. Esse vídeo teria a intenção de disponibilizar os resultados da aula visita para a comunidade, pais e responsáveis e a quaisquer interessados na causa socioambiental. Nos comentários do vídeo, as pessoas poderiam interagir expressando suas sugestões, opiniões ou relatando experiências similares realizadas por outras escolas, com a finalidade de demonstrar o zoológico como um espaço educativo, a despeito de suas supostas adversidades de manutenção. Essa divulgação deveria ser difundida de forma a sensibilizar a sociedade, atraindo as autoridades públicas e iniciativa privada no sentido de incitá-los a uma mobilização em prol de sua readequação. Em relação ao zoológico, houve também a intenção de promover uma "conversa institucional" para além da aprendizagem propriamente dita, com eventual acolhida de ideias e sugestões por parte de seus gestores, na consecução de um diálogo horizontal.

Em abril do ano 2015, foi realizada uma abordagem informal dos gestores do zoológico, com coleta de endereços eletrônicos destinados ao envio da correspondência necessária ao seguimento da entrevista. Em 14 de abril, foi remetido o projeto da aula visita e um questionário com 15 perguntas passíveis de análise por gestores da área de veterinária. Essa análise deveria depurar o instrumento em um formato adequado para uso pelos estudantes na entrevista (Quadro 1).

Quadro 1: Questões enviadas previamente aos gestores do zoológico da UFMT em abril de 2015

\section{Questões enviadas aos gestores do zoológico para apreciação}

1. Qual é a origem dos animais do zoológico?

2. Em relação ao espaço de cada animal no zoo, é correto o uso da palavra jaula? Caso não seja, qual é o termo correto?

3. Quais são os procedimentos padrões de acolhida de um animal quando ele chega ao zoo?

4. A fauna de qual ecossistema é representada aqui?

5. Quando o zoológico foi criado?

6. Qual faculdade da UFMT cuida do zoológico?

7. Quem provê verbas para a manutenção do zoológico?

8. Quantas refeições os animais recebem por dia?

9. Quais são os comportamentos mais perniciosos dos visitantes em relação aos animais e ao zoológico em si?

10. O que vocês gostariam que fosse melhorado no zoológico?

11. O que é feito com animais solitários na época do estro?

12. O que vocês fazem para evitar endocruzamento entre animais de uma mesma jaula?

13. Quais são os efeitos do confinamento a médio e longo prazo para a saúde dos animais?

14. Quais são as espécies do zoo mais ameaçadas de extinção?

15. Existem influências externas ao zoo que comprometem seu funcionamento? Quais?

Fonte: A autora (2015) 
DOI: http://dx.doi.org/10.33238/ReBECEM.2019.v.3.n.1.21961

As questões de número 11 e 12 surgiram na sala de aula, a partir das dúvidas dos estudantes. Na escola, os estudantes formaram grupos organizados por critério de afinidade, com duas a quatro pessoas. Ainda em sala de aula eles receberam um roteiro com o objetivo da aula visita, dialogaram sobre as ações e fizeram escolhas acerca das mesmas. Após esse acordo logístico, a coordenação pedagógica providenciou solicitações de autorização aos pais e responsáveis para a visitação. Nessa autorização que seria endereçada aos responsáveis, constava data da aula visita, horário de saída e retorno e o objetivo da mesma. O transporte foi alocado pelos próprios estudantes. As ações a serem executadas pelos estudantes na aula visita ao zoológico são mencionadas na Quadro 2.

Quadro 2: Atividades discentes prescritas e seus respectivos objetivos na aula visita ao zoológico da UFMT

\begin{tabular}{|c|c|}
\hline Ação esperada & Objetivo \\
\hline Fotografar & $\begin{array}{l}\text { Obter imagens dos animais nos recintos, considerando a aptidão dos estudantes } \\
\text { para utilizar os celulares nesta tarefa. Foi dito que fizessem "selfies" das onças e } \\
\text { outros animais à vontade. }\end{array}$ \\
\hline $\begin{array}{l}\text { Desenhar planta } \\
\text { baixa }\end{array}$ & $\begin{array}{l}\text { Valorizar a aptidão para o desenho expressa por alguns discentes e ao obter o } \\
\text { desenho, realizar comparações com imagens obtidas do local no Google Maps. }\end{array}$ \\
\hline $\begin{array}{l}\text { Entrevistar } \\
\text { visitantes }\end{array}$ & Obter opiniões das pessoas sobre o lugar e sua infraestrutura. \\
\hline Filmar & $\begin{array}{l}\text { Filmar os animais nos recintos, buscando aproveitar os achados para associá-los } \\
\text { a conteúdos de Zoologia trabalhados na sala de aula. }\end{array}$ \\
\hline $\begin{array}{l}\text { Observar placas e } \\
\text { anotar seu conteúdo }\end{array}$ & $\begin{array}{l}\text { Percepção da importância do uso de nomes regionais e científicos, da } \\
\text { classificação biológica, bem como, da categorização das normas de nomenclatura } \\
\text { taxonômica. }\end{array}$ \\
\hline $\begin{array}{l}\text { Aspirar a } \\
\text { empreender }\end{array}$ & $\begin{array}{l}\text { Obter dos alunos um olhar sobre como o zoológico poderia explorar } \\
\text { comercialmente a visitação, com base na infraestrutura presente na atualidade. }\end{array}$ \\
\hline $\begin{array}{l}\text { Entrevistar } \\
\text { veterinários do } \\
\text { zoológico }\end{array}$ & $\begin{array}{l}\text { Obter informações básicas sobre a alocação, manejo e ambientação dos animais } \\
\text { no zoológico. Sondagem de condutas dos visitantes tidas como perniciosas para } \\
\text { os animais e a manutenção do espaço físico local. }\end{array}$ \\
\hline
\end{tabular}
Fonte: A autora (2015)

Anteriormente à saída, firmou-se uma agenda de recomendações acerca das tarefas entre professora e estudantes. A primeira parte da visita seria exploratória e coletiva, na segunda parte, os grupos realizariam as tarefas predeterminadas e num terceiro momento, todos se reuniriam para entregar suas coletas à professora.

Todos foram sensibilizados a agir seriamente durante a realização das tarefas. A aula em ambiente não formal, areja a mente, mobiliza o corpo e deve também propiciar algum lazer aos adolescentes, desde que se estabeleçam momentos específicos para tais 
DOI: http://dx.doi.org/10.33238/ReBECEM.2019.v.3.n.1.21961

fins. Há um limite tênue no contexto dessas ações como práticas pedagógicas ou como meras "escapadas" da sala de aula para simplesmente passear, onde

reconhece-se a grande necessidade de inovar no âmbito escolar. Práticas de ensino instigantes e que permitam aos sujeitos o desenvolvimento da capacidade de "aprender a aprender" são de grande importância [...] (CARDOSO; GATTIBONI, 2015, p.92).

Os alunos consideram positivos e alternativos à rotina, um método de aprendizagem que não contenha apenas escrita e teoria. Quando estão relaxados, eles ficam mais aptos a absorver conhecimento e a cooperar entre si e com o professor (PUHEK; PERŠE; ŠORGO, 2011).

\section{Resultados e discussões}

A entrevista enviada aos gestores da área de veterinária do zoológico da UFMT não teve responsividade. Professora e discentes também não receberam nenhuma orientação quanto à possível existência de monitores no zoológico aptos a acompanharem visitantes oriundos de escolas. Sequer ocorreu resposta negativa formal em relação ao projeto. Portanto, considera-se que não houve interesse por parte do zoológico na proposta de ensino-aprendizagem, tampouco em suas intenções subjacentes. Diante de tal situação, a aula visita foi readequada e realizada de acordo com a data planejada.

Em 07/05/2015, no período vespertino, os estudantes do $2^{\circ}$ Ano $\mathrm{H}$ e docente de Biologia foram ao zoológico da UFMT para a realização da aula visita. Na chegada, fizeram um percurso panorâmico com a professora, que discorreu sobre generalidades do ambiente e animais. Após aproximadamente trinta minutos, os grupos se dispersaram para realizar suas tarefas, baseadas em escrita e uso de Tecnologias Digitais de Informação e Comunicação (TDIC) portáteis (câmeras de smartphones). Seis estudantes fizeram quarenta fotos de animais. Foram divididos em três duplas para fotografar aves, mamíferos e répteis. Ainda no zoológico, mixavam as fotos em criativos arranjos utilizando filtros de uma rede social e faziam postagens simultâneas em seus perfis. Valente e Almeida (2014), mencionam que as TDIC disponibilizam aos usuários recursos conhecidos como affordance, por facilitarem a obtenção de informações, participação em experiências e mobilização de habilidades.

Por meio desses recursos é possível interagir com pessoas, via voz ou mensagem escrita, imagem estática ou em movimento, ter acesso a conteúdo armazenado localmente no dispositivo em uso ou acessado via conectividade, e acesso a 
DOI: http://dx.doi.org/10.33238/ReBECEM.2019.v.3.n.1.21961

serviços, considerados como conteúdo dinamicamente gerado (VALENTE; ALMEIDA, 2014, p.35).

Uma dupla de estudantes fez filmagens, filmando o passeio local e os recintos. Essas filmagens seriam aproveitadas na confecção do vídeo sobre a aula visita. Dois estudantes percorriam o zoológico para tentar esboçar uma planta baixa, que depois seria melhorada e colorizada a lápis de cor. Esse desenho seria digitalizado posteriormente. O desenho é uma expressão muito apreciada pelos discentes, confirmando que "[...] nenhuma técnica conseguirá prepará-lo melhor do que aquela que incita as crianças a se exprimirem pela palavra, pela escrita, pelo desenho e pela gravura" (FREINET, 2004, p.25).

Outros três estudantes fizeram entrevistas com visitantes. Previamente receberam orientação para abordar as pessoas com cautela, apresentando os objetivos da entrevista e somente após anuência, coletar as respostas. O número de questões foi equivalente a três, elaborada pelos próprios estudantes e versou sobre o que seria bom no zoológico, o que seria negativo e sugestões para melhorar o local como um todo. Duas famílias presentes colaboraram com a tarefa.

Oito estudantes percorreram o zoológico anotando informações das placas. Perceberam que algumas placas estavam desbotadas, sem uniformidade na arte e, mesmo, eram ausentes em alguns recintos. Existiam recintos que sequer continham animais.

Duas estudantes fizeram um relatório com suas ideias sobre como o zoológico poderia empreender para obter lucros com a visitação. Mencionaram que poderia haver uma catraca na entrada do espaço para a cobrança de ingressos. Logo na entrada, à direita, há uma construção vazia, que mencionaram poder servir para a instalação de uma lanchonete e ponto para venda de souvenires. Pressupõe-se que atualmente a essa construção eventualmente seja utilizada como um espaço para preleções. Também sugeriram que visitas monitoradas taxadas poderiam ser viáveis e que as receitas obtidas poderiam ser revertidas para complementar os custos de manutenção do zoológico.

No momento da visita panorâmica, os estudantes manifestaram profícua curiosidade, expressando as seguintes perguntas (transcrição):

E1: Se o lobo-guará é um canídeo, então ele ataca pessoas?

E2: Por que esse cachorro-vinagre é tão fedido?

E3: Por que há uma onça preta junto com as onças pintadas?

E4: Cadê a jiboia dentro do recinto?... Ah! Só agora consegui enxergar.

E5: Por que o tamanduá tem um focinho tão comprido? 
DOI: http://dx.doi.org/10.33238/ReBECEM.2019.v.3.n.1.21961

Diante de tais perguntas, a professora pôde discorrer sobre aspectos ecológicos, etológicos, fisiológicos e anatômicos inerentes aos animais mencionados. Em sala de aula, abordando o estudo desses animais a partir de um livro didático, certamente tais indagações nunca aconteceriam. Comumente há um silêncio após as explicações, tido como expressão de entendimento sobre o assunto pelos estudantes e ligeira contemplação das imagens estáticas presentes nas fotografias do livro. Esse ambiente destituído de criatividade é consequência de um evento que se justifica no fato de que

Somos uma geração de copistas-copiadores, de repetidores condenados a registrar e a explicar o que dizem ou fazem homens que nos afirmam ser superiores e que, muitas vezes, só têm sobre nós o privilégio da antiguidade nessa arte de copiadores e de repetidores (FREINET, 2004, p.26).

Freinet fez uso de muitas outras técnicas de ensino que permitem a ação efetiva dos estudantes, tais como o desenho livre, o mural de exposição de trabalhos, os cantos de interesse, a aula-passeio (FORTUNATO, 2016, p.252). Neste momento já não importa a terminologia, seja aula visita ou aula-passeio, visto que seus objetivos tiveram convergência na possibilidade de transpor os estudantes para um ambiente ao ar livre, com autonomia para realizar tarefas, oportunidade de aprender e também ocasião para recrear.

Houve nesta proposta um esforço de criação pessoal, como o próprio Freinet procurou ensinar, com produção de materiais de mídia e escrita pelos estudantes, posteriormente entregues para a professora. As fotos foram enviadas através da rede de uma social de mensagens instanstâneas de celular, ficando pendentes para posterior entrega, os vídeos e o desenho finalizado da planta baixa. Esses dois últimos itens nunca foram entregues para uso na compilação de materiais produzidos na aula visita.

Essa aula visita foi às vésperas do afastamento da docente organizadora da aula visita para qualificação em programa de mestrado. Todo o material fotográfico coletado na ocasião pela professora foi selecionado, bem como informações presentes nos relatórios e obtidas nas entrevistas e posteriormente compilado em um vídeo intitulado "Aula visita no Zoológico da UFMT"2, então disponibilizado em uma plataforma para reprodução e difusão de material audiovisual. $\mathrm{O}$ vídeo foi produzido com recursos do

\footnotetext{
${ }^{2}$ Disponível em: 〈https://youtu.be/Z7fezrRQ9Xk>. Acesso em: 08 abr. 2019.
} 
DOI: http://dx.doi.org/10.33238/ReBECEM.2019.v.3.n.1.21961

editor gráfico Microsoft Office PowerPoint ${ }^{\circledR}$, possuindo como trilha sonora a música Bolero de Ravel, disponível livre de direitos autorais na mesma plataforma.

O vídeo contém poucas fotos obtidas a partir do Google Images, como é o caso da foto de um casal de lobos guarás e da planta lobeira. A produção deste material se alinha à proposição dos autores De Almeida e Valente (2012) de que textos e imagens podem ser facilmente manipulados, alterando o modo de uso, interpretação e transformação da linguagem verbal e visual. Os avanços nas tecnologias disponibilizam recursos digitais úteis na animação de histórias que fundem recursos imagéticos, sonoros e dinâmicos, sem que os usuários dessas ferramentas sejam necessariamente especialistas no assunto. Assim, o PowerPoint pode, entre outros aplicativos, ser utilizado para a produção de narrativas (DE ALMEIDA; VALENTE, 2012), como foi feito na compilação de materiais oriundos da aula visita, mixados a imagens obtidas em rede, sob a forma de um vídeo. $\mathrm{O}$ vídeo possui imagens produzidas pelos estudantes com uso de filtros existentes em redes sociais (Figura 1). Assim, os familiares e pessoas conectadas aos estudantes nesses locais do ciberespaço viam em tempo real suas atividades em campo.

Figura 1: Captura de tela obtida para demonstração de fotografia produzida pelos estudantes com uso de recursos para a mixagem de imagens

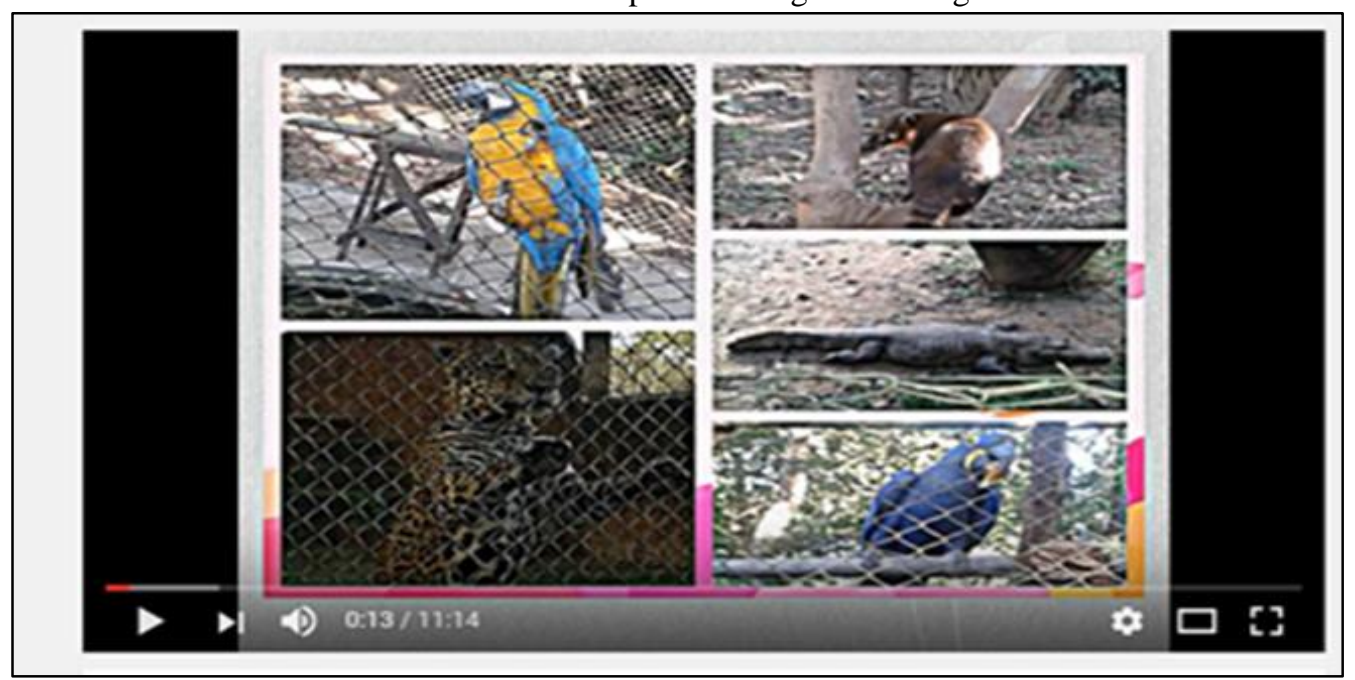

Fonte: Arquivo da autora (2015)

$\mathrm{Na}$ construção do vídeo, as mesmas imagens foram encadeadas na trama com objetivo de mostrar a criatividade discente no manejo com recursos digitais de mídia e mesmo a beleza dos animais existentes no zoológico. Em um contraponto com imagens até então difundidas em alguns sites, deveras depreciativas, que procuravam expor os animais como se estivessem doentes ou submetidos a maus tratos. 
A opinião acerca da própria concepção do zoológico enquanto instituição é expressa pela estudante "X" (Figura 2). No excerto, é possível deduzir que os estudantes conceberam o zoológico como um local de "asilo" para espécies ameaçadas de extinção. É fato que o zoológico da UFMT recebe animais oriundos de apreensão em cativeiros. Muitos deles não reconheceriam mais os seus respectivos nichos ecológicos se soltos nos habitats naturais.

Figura 2: Excerto de trecho do relatório produzido pelos estudantes sobre a aula visita

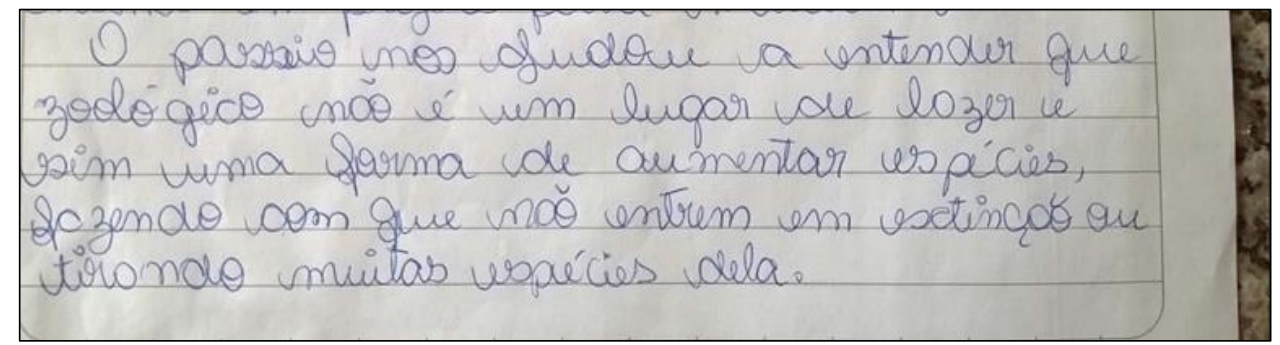

Fonte: Produções dos discentes (2015)

A compilação que resultou no vídeo aula visita ao Zoológico da UFMT apresentou-se como uma modalidade de narrativa digital porque consiste em um enredo, uma trama ou mero relato com o texto, a imagem, o som [...] traduzidos digitalmente e, assim, trabalhados por um único dispositivo, o computador (DE ALMEIDA; VALENTE, 2012, p.65). Mas tecnicamente segue uma trama linear cujos elementos utilizados não podem ser alterados, seguindo os passos de relatos mais tradicionais. São as narrativas clássicas lineares, ainda que produzidas no mundo virtual. Neste caso, os usuários passivamente observam o desenrolar da trama previamente estabelecida pelo produtor (DE ALMEIDA; VALENTE, 2012, p.66). Esses autores citam três elementos das narrativas digitais consagrados por Murray, tais como a imersão, a agência e a transformação.

A imersão está relacionada com o fato de os produtores e usuários serem transportados para outros mundos ficcionais, anulando temporariamente o mundo em que vivemos, sem sairmos do lugar. A agência está relacionada com o fato de podermos realizar ações significativas e ver seus resultados quase instantaneamente. Se estes resultados não correspondem ao que imaginamos, as mudanças podem ser feitas sem maiores prejuízos. E, finalmente, a transformação permite ao usuário ter a liberdade de seguir uma jornada própria, podendo alterar o que desejar, devido à plasticidade das TDIC, que possibilitam o fazer e refazer contínuo (ALMEIDA; VALENTE, 2012, p.66). 
DOI: http://dx.doi.org/10.33238/ReBECEM.2019.v.3.n.1.21961

Apropriando-se livremente dos conceitos de imersão, agência e transformação, poder-se-ia perfilar o vídeo como uma narrativa digital em decorrência das seguintes situações: ele transporta virtualmente seus espectadores para um ambiente fisicamente existente, como o zoológico (imersão) e uma prática pedagógica; o espectador pode envolver-se com a trama e contemplá-la como se fosse: um visitante virtual do zoológico, um educador adquirindo ideias para uma prática, alguém que assiste e interage com outros espectadores anteriores ao comentar o vídeo e mesmo, como alguém que o assiste e permanece indiferente ao seu teor. Essas ações se traduzem nas escolhas quanto ao modo de agir (agência); a possibilidade de editar o vídeo, inserindo links, removendo imagens ou mesmo alterando sua trama para remodelar seu objetivo como material imagético sinaliza a possibilidade de remodelação desses recursos (transformação). "Nestas histórias a audiência ganha possibilidades para escolher, mesmo dentro de opções restritas à sua perspectiva do enredo" (MIYAMARU, 2003, p.2).

Atualmente as narrativas digitais não possuem apenas perfil linear, podendo ser hipermodais ao inserirem hipermídia em seus contextos, dando ao leitor múltiplas formas de interagir com o conteúdo ou trama.

O ambiente virtual é geralmente estático e não treina habilidades manuais tal como o campo, porém a atividade dos estudantes seria preservada de qualquer maneira. Não resta dúvida de que é melhor observar e trabalhar no ambiente natural "real", mas recursos baseados em TDIC podem constar como substituição ideal nos casos em que isso não é possível ou, que não haja um ambiente para a articulação e prática. Uma viagem de campo virtual pode ser comparada a um filme, filmado após um livro (apresentado como trabalho de campo real). Todos sugerem que ler um livro é bom, mas assistir o filme é simplesmente incrível (PUHEK; PERŠE; ŠORGO, 2011). Pela propriedade de imersão, um espectador remoto poderia ser transposto virtualmente ao zoológico da UFMT. Não exatamente nos moldes de uma caverna digital ou do holodeck de Janet Murray, mas possibilitando alguma impressão acerca do zoológico aos espectadores de outros lugares. A prática da escrita exortada por Freinet, como um meio de correspondência entre estudantes de diferentes escolas, também não deixa de ser evocada no recurso da vídeocompilação como narrativa digital. Os comentários, desde que ativos no vídeo, constam como um campo do ciberespeaço para a realização dessa correspondência e troca de 
DOI: http://dx.doi.org/10.33238/ReBECEM.2019.v.3.n.1.21961

ideias. Será que nesse ínterim, também seriam os espectadores, nós ativos na rede outrora metaforizada por George Siemens na proposição do Conectivismo?

O compartilhamento do conteúdo, por exemplo, é iniciado por colegas de classe e professores, com possíveis contribuições dos núcleos familiares pela recirculação dos vídeos (QUADROS; QUADROS JR., 2013). E essa disseminação pode também ter consonância com algo que Martins, Rancura e Oliveira (2016) denominam como ação educativa participativa. Deste evento surgiria a mobilização social almejada com a postagem do vídeo, por entes de diversos segmentos sociais, incluindo inciativa privada, levando (ou não) ao surgimento de parcerias potenciais para desencadear a necessária readequação do zoológico, contanto que houvesse receptividade de seus gestores. Ocorre que não houve acolhida da proposta pelos gestores, tampouco qualquer tipo de resposta, além do silêncio propriamente dito. Permaneceu a autora deste trabalho e seus discentes em aparente monólogo com suas próprias intenções quanto ao zoológico, ao invés do diálogo pensado inicialmente, configurando-se, portanto, uma comunicação unilateral do ponto de vista das instituições escola-zoológico. Um monólogo porquanto,

\begin{abstract}
Não podemos deixar de lembrar que, para Mikhail Bakhtin, não há comunicação se não houver uma reciprocidade no diálogo. Comunicando-se, o homem reconhece-se no outro e, nessa relação de alteridade, adquire autoconhecimento. Em suas investigações, Bakhtin coloca a questão da intersubjetividade como fundamental. Ser é comunicar e é ser para um outro e também para si. Assim, nos reconhecemos em um outro que, embora não consideremos igual a nós mesmos, nos identificamos (GRÉGIS, 2006, p.6).
\end{abstract}

E do ponto de vista desta identificação, que urgiu diante do panorama de desconstrução discursiva do zoológico, enquanto um acervo fanunístico de relevância social e universitária, a prévia idealização de diálogo institucional foi frustrada. Percebemos que a instituição não tinha intenção de estabelecer comunicação com a pesquisadora, sua proposta e seus estudantes. Entretanto, do ponto de vista da perspectiva professoradiscentes, houve comunicação.

A aula visita resgatou inconscientemente o modelo de aula-passeio, como proposto por Freinet, porque possibilitou a criação quase intuitiva de uma narrativa digital linear com os materiais produzidos pelos estudantes em campo. Neste sentido, a aula visita foi um diálogo entre estudantes e docente, além de possibilitar oportunidade para aquisição de conhecimentos a todos os seus envolvidos. Ainda com o interregno causado pelo afastamento da docente, para qualificação profissional, houve produtividade dos discentes e empenho nas atividades propostas. A única atividade discente que não teve 
DOI: http://dx.doi.org/10.33238/ReBECEM.2019.v.3.n.1.21961

devolutiva para a professora foi a planta baixa desenhada em campo. Certamente sua coleta poderia ter colaborado para tornar mais consistente o argumento do vídeo.

A compilação deu à autora oportunidade de inteirar-se do próprio conceito de narrativa digital, abrindo precedente para futuras práticas com uso desta metodologia. E a presença do vídeo no ciberespaço não impede que o aparente monólogo se transforme com o tempo, em um diálogo entre diferentes atores sociais e educadores, propiciando um protagonismo digital e social que se traduza em ações concretas para a superação de um processo de crise socioambiental existente no zoológico da UFMT, vislumbrada em suas múltiplas facetas.

\section{Considerações finais}

A aula visita como experiência em ambiente não formal de ensino foi apreciada por parte dos estudantes. Constando como uma oportunidade de aprendizagem além das paredes da sala de aula, mobilizou sua idealizadora na aquisição de registros da atividade em campo, que posteriormente foram compilados em um vídeo. Constata-se que o vídeo construído com recursos informáticos simples, produziu uma narração da experiência nos moldes aproximados de uma narrativa digital linear.

O vídeo enquanto produto da aula visita traz uma visão alternativa do zoológico da UFMT, mas não deixa de ter um roteiro pedagógico embutido em sua proposta. Cada espectador escolhe a destinação da exibição, seja como um viajante virtual no zoológico da UFMT ou como um educador em busca de ideias para aulas em ambientes não formais de ensino. De qualquer forma, almeja-se que a instituição zoológica visitada, continue relevante para a sua comunidade de inserção, principalmente por sua importância enquanto ambiente que recebe animais ameaçados de extinção ou recolhidos de cativeiros. Que o uso responsável de mídias digitais para mobilização social surta efeitos na readequação do zoológico, a despeito do silêncio de seus gestores em relação a proposta de ensino-aprendizagem e parceria ofertada, enquanto um convite ao diálogo institucional e pedagógico.

Porém, essa construção deslindou as deficiências que grassam a realidade de estudantes e professores na educação básica: eventuais (e reais) fissuras digitais transcendem a simples boa intenção ou eventual instinto maker dos docentes, corroborando necessária cautela na criação e difusão de mídias imagéticas. Os docentes 
DOI: http://dx.doi.org/10.33238/ReBECEM.2019.v.3.n.1.21961

e estudantes podem estar à margem do processo, quando desconhecem as regras éticas e legais necessárias para a viabilização de propostas semelhantes, e que não redundem em situações potencialmente deletérias para os envolvidos no processo. Uma aula de campo que resulte em narrativa digital consta como um caminho alternativo e plausível no fazer pedagógico da atualidade. Atentos estejam os docentes que as realizarem, em relação a tropeços potenciais nessas trilhas, especialmente os da seara ética e legal envolvendo imagens e vozes de jovens e adolescentes.

\section{Referências}

CARDOSO, H. R.; GATTIBONI, M. de L. S. Turismo pedagógico: uma alternativa para integração curricular. Professare, Caçador, v. 4, n. 1, p. 85-110, 2015.

DE ALMEIDA, M. E. B.; VALENTE, J. A. Integração currículo e tecnologias e a produção de narrativas digitais. Currículo sem fronteiras, v. 12, n. 3, p. 57-82, 2012.

DE QUADROS, C. I. et al. Aspectos comunicacionais da educação nas mídias sociais digitais: o caso do YouTube. Ação Midiática - Estudos em Comunicação, Sociedade e Cultura, n. 5, 2013.

FREDERICCI, D. Zoológico da UFMT vive fase melancólica. Circuito MT, abr. 2015. Disponível em:<http://circuitomt.com.br/editorias/cidades/65229-zoologico-da-ufmt-vive-fasemelancolica.html\#> Acesso em: 17 jul. 2017.

FERREIRA, B. Os Zoológicos do Futuro Não Terão Jaulas. Motherboard. Disponível em: $<$ https://motherboard.vice.com/pt_br/article/os-zoologicos-do-futuro-no-terao-jaulas >. Acesso em: 08 ago. 2017.

FORESTI, A.; TEIXEIRA, A. C. Proposta de um conceito de aprendizagem para a era digital/Proposal a concept of learning for the digital age. Revista Latinoamericana de Tecnologia Educativa - RELATEC, v. 11, n. 2, p. 55-68, 2012.

FORTUNATO, I. Aprendendo com Célestin Freinet: o passado ainda é presente. Learning from Célestin Freinet: the past is still present. Tendencias Pedagógicas, n. 27, 2016.

FREINET, C.; BATISTA, J. Pedagogia do bom senso. São Paulo: Martins Fontes, 2004.

GRÉGIS, R. A. A alteridade no monólogo. Revista Virtual de Estudos da Linguagem ReVEL, v. 4, n. 6, p. 1-7, 2006.

GOLDSCHMIDT, A. I. Professor, o que fazer no zoológico? Revista Ciências \& Ideias, v. 7, n. 3, p. 60-87, 2017.

JACOBUCCI, D. F. C. Contribuições dos espaços não-formais de educação para a formação da cultura científica. Em Extensão, Uberlândia, v. 7, p. 55-66, 2008.

MARTINS, C.; RANCURA, K. G. DE OLIVEIRA; OLIVEIRA, H. T. DE As metodologias participativas no processo de elaboração de espaços educadores em zoológicos em uma 
DOI: http://dx.doi.org/10.33238/ReBECEM.2019.v.3.n.1.21961

perspectiva de educação ambiental crítica. Revista Eletrônica do Mestrado em Educação Ambiental - REMEA, v. 33, n. 1, p. 307-326, 2016.

MIYAMARU, F. et al. Hamlet no holodeck o futuro da narrativa no ciberespaço, por Janet Murray. São Paulo: UNESP, 2003.

NEVES, P. Baixo peso de onças do zoológico da UFMT chama a atenção de visitantes. Olhar Direto, Notícias/cidades, jul. 2016. Disponível em:

<http://www.olhardireto.com.br/noticias/exibir.asp?id=423837\&noticia=baixo-peso-de-oncasdo-zoologico-da-ufmt-chama-a-atencao-de-visitantes>. Acesso em: 14 jun.2017.

PUHEK, M; PERŠE, M.; ŠORGO, A. Students' Perceptions of Real and Virtual Fieldwork in Biology. Problems of Education in the 21st Century, v. 37, p. 98-108, 2011.

TRIPP, D. Pesquisa-ação: uma introdução metodológica. Educação e pesquisa, v. 31, n. 3, 2005.

VALENTE, J.; DE ALMEIDA, M. E. B. Narrativas digitais e o estudo de contextos de aprendizagem. EaD EmRede - Revista de Educação a Distância, v. 1, n. 1, p. 32-50, 2014.

Recebido em: 21 de março de 2019.

Aceito em: 11 de abril de 2019. 